\title{
Product Ethnicity between the Hammer of Identity and the Anvil of Globalization
}

\author{
Jeddi Nabil $^{1^{*}}$, Zaiem Imed ${ }^{2}$ \\ ${ }^{1}$ Faculty of Economic Sciences and Management of Tunis, Campus Universitaire, El Manar II, Tunis; ${ }^{2}$ Department of Management, \\ Carthage University, Campus Universitaire Mrezgua, Nabeul, Tunisia. \\ Email: *nabil.jeddi@yahoo.fr, imed.zaiem@fsegt.rnu.tn
}

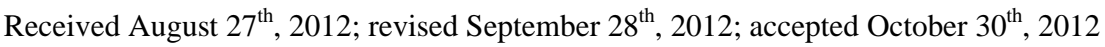

\begin{abstract}
With the globalization of markets, the multinational production made obvious great strides marked by the proliferation of hybrid or bi-national products. In this context which supported the dissolution of identity of several products' categories and called in question the weight of origin labels about the consumer behavior purchase. Beyond these reflections, this article proposed to wonder about the relation between globalization and product ethnicity, by analyzing the apparent effects of the current context of globalization on the establishment of stereotypic country-products associations by the consumers. Also, the question which is directed to the development and the presentation of this research is the following one: to what extend does the current context of globalization enable us to call in question the phenomenon of product ethnicity?
\end{abstract}

Keywords: Product Ethnicity; Globalization; Country of Origin; Hybrid Products; Stereotypic Associations

\section{Introduction}

Today, research in international marketing covers, more and more, a great importance evolving with the globalization of the production. Within this framework, the country's origin effect remains one of the most studied fields since it represents a mirror reflecting the ascent of the total markets complexity.

Thus, although work for this reason seems numerous and varied, few researches only are leaning on the treatment of the bonds stereotypic established by the consumer between particular countries and some specific products (the product ethnicity). However, it would act, to tell the truth, this topic has a major importance insofar as the association of the country's images to the product category characteristics, would make it possible to the managers a best comprehension of the formations preferably for such products, and consequently, to provide a meticulous analysis of the consumer attitudes with regard to the products manufactured in particular countries [1].

However, in a current context of globalization marked by a stressing of jamming strategies origin giving rise to multinational corporations and hybrid products, the phenomenon of the product ethnicity seems to be dissimulated because of the distance which can emerge between the product and its origin. As a consequence of the globalization, it became necessary to revisit the notion of

*Corresponding author. ethnicity in order to reposit it adequately in the current situation.

\section{Conceptual Framework of Research}

Considering the increasing evolution of the offer and the eagerness of competition on the international market, consumers are flooded with a multitude of brands and varied products resulting from various origins. However, as indicated in many researches, the majority of the countries often do not present that a restricted number of products categories particularly typical in which they excel [2] and which the consumers associate stereotyped images. In this direction, the bonds and associations established between particular countries and some products specific, belong to the universe of the consumers [3]. These bonds, qualified "products ethnicity", contribute thus to a better comprehension of the consumer behavior, in particular, in a globalization' context of the markets which are marked by the increased emergence of hybrid products.

\subsection{Product Ethnicity Theory}

Admittedly, some products referent systematically with a particular countries on which they are dependent typically, other products are associated with several countries as the case of the cars which can be associated with 
Germany, Japan, the United States... While the majority of the products are neutral thus not evoking any country [3]. Within such a framework it registered the concept of "the product ethnicity" which finds its roots in the "bonds product-countries" developed by Roth and Romeo in 1992.

The majority of research which approached the topic of ethnicity it often associated with nationality and the nation, owing to the fact that such a term goes up its source in ancient Greece "Ethnos" to mean the nation or the people, and since, this concept always maintains this basic significance [4]. Usually, the ethnicity was perceived in logic of localization and membership. Indeed, according to Wade (1997) [5], such a concept can be defined by its association in a place thus giving form to the cultural difference. So the description of the ethnicity in terms of originating authenticity and cultural continuity often returns to an analysis dominated by the concepts of identity construction, multiplicity of the memberships and indetermination of the attributes [6].

Within the framework of our research, to the risk of getting bogged, we will not approach the concept of sociological ethnicity as category since the various definitions suggested by the sociologists on this subject seem complex and difficult to encircle considering their semantic and ideological base. However, we will concentrate on the treatment of this concept while basing ourselves on a review of literature marketing.

In optics marketing, it appears clear that the stereotypes play a capital part in the image of the country [7]. Indeed, associations between country and products often established by the consumers make, inter Alia, started from their universe and are formed while being based on true information which is transformed thereafter into stereotypes [3]. While referring to this reasoning, the Japanese consumers associate, for example, Germany and France with the long history and the tradition, Switzerland and Australia with the richness of nature and the United States with the advance of industrial technologies [8]. In such a context, "the product ethnicity" is which refers to the stereotypic associations established by the consumers between a generic product and a particular country of origin [8]. These qualified associations of "bonds product-country" by Roth and Romeo (1992) can go in the two directions; they are then either bonds product-country or of bonds country-product. Moreover, such associations cannot be established in the same way by the consumers of various countries.

While referring to these researches, Usunier (2002) defines the ethnicity as being the whole "of bonds stereotypic establish by the consumers between countries and products and founded on perception that a country has a know-how and a reputation established for a particular generic product” (p. 35). The author adds that ethnicity "as a strong association made between a country and a product" can be also considered as being "a form of typicality" which can come from various sources: of a place adapted by the natural resources (called by the economists factorial equipments), of a knowledge to make traditional which was developed in the manufacture of this product insofar as it is about the country's origin of the invention and the country's development of the product (such is the example of the scooter invented in the United States but developed in Italy), or of an exclusive association established with a very typical brand of the country in question, etc.

As a synthesis, one can admit that the ethnicity of the products can be generally regarded as being “a strong association established by the consumer between a particular country and a generic product with the result that such a country is recognized typically by this product and reciprocally”.

\subsection{Various Forms of the Product Ethnicity}

While referring to studies undertaken by Usunier in various countries whose objective was to measure the representations of the couples country-products and product-country, it appears that there are several shapes of product ethnicity. For this purpose, while being focused on the study of the direction, the intensity and the exclusiveness in the character of various associations which can exist between countries and products, Usunier (2002) distinguishes three types of product ethnicity: the simple ethnicity, the strong ethnicity and the global ethnicity, which it proposes to allot to them the following formal definitions:

\subsubsection{Simple Ethnicity}

This form of ethnicity represents a simple association established by the consumers between country and product. In this case, the process of categorization can go in the two directions, i.e. that a country can evoke a product and reciprocally a product can in its turn evoke a country. Thus it will be simple ethnicity country-product or ethnicity simple product-country.

\subsubsection{Strong Ethnicity}

The force of product ethnicity returns, amongst other things, with an exclusive association product-country. In other words, ethnicity is known as strong when associations (in the two directions) have a high degree of exclusiveness. Thus, it seems obvious that the consumers of various countries cannot make similar association's country-product inevitably. However, Usunier (2002) claims that by combining the simple ethnicities in various national contexts, it would be possible to have a bond established by the consumers in an international context thus leading to a strong ethnicity. 


\subsubsection{Global Ethnicity}

This form of ethnicity refers to the clearly ethnic products for which an association country-product strong and bi-univocal emerges. It is about a country which evokes a product exclusively and this last evokes in its turn this country; even if not exclusively, a country strongly evokes a product and vice versa the latter evokes in a particular way this country compared to the other countries.

\section{The Product Ethnicity Revisited by Globalization}

Today, in a context marked by the multinationalisation of the companies and the intense proliferation of brands of various origins, the stereotypic associations established by the consumer between countries and products can weaken towards many taxonomies (country of origin, country of manufacture, country of the "made in", etc.) who are varied and complex [9]. In this case, there is nothing surprising so that the companies are all the more satisfied on the strong points with the image "made in" reinforcing the identification of their products and to allot favorable constellations to them.

\subsection{A Handing-Over in Question of Origin Labeling or "Made-In"}

For better informing the consumers, and to face the proliferation of the counterfeits and to mitigate incidence of the fraudulent stamps origins, OMC (World Organization of Trade) intervened to regularize and harmonize, at the world level, the rules of marking origin products.

However, in spite of all these procedures, one attends more and more an ambiguity of the information countryof-origin in the regulation of international trade due to the adoption of too vague indications of origin or even sometimes to the absence of these labels straightforwardly. As a result, it would be a question of re-examining the practices of marking origin and the laws which govern them.

It is certain that origin rules should not be discriminatory with respect to the products of some countries. Indeed, for OMC these rules will not have to constitute a political instrument [3]. However, the companies adopt more and more strategies of jamming as for the source of their products while reducing to judicious information being posted on the products. In other words, they deliberately post vague and not very informative mentions on their products like "Made in Europe" or "Made in Asia" in order to return the information of the origin less and less available for the consumer.

On this subject, recent research confirms that the seals of origin less and less clearly appear on the products that they are not it there are 2 or 3 decades [3]. According to him, the appearance of such labels seems to be wished neither by the multinational firms which aim at veiling the origin of their goods within the framework of the total system of "sourcing" that they adopt, nor by the authorities of the total trade which consider the appearance of these seals of origin as being a form of "potential discrimination" with respect to the products of the developed countries and thus regard them as a handicap with the participation of the emergent countries or weak image in the world trade.

For all these reasons, many companies abstain from mentioning the origin of their products on the products themselves, it is what explains progressive disappearance mainly, on the one hand, of the informational characteristic conveyed by the another share and seal of origin the appearance of too vague labels which can even sometimes be whimsical [3] or rather complicated.

Consequently, it became rather difficult to restrict the notion of "made-in" with a particular country when it can cover a soil or even a whole continental zone like the case often with the Asian products [10]. Thus, this key of information does not seem available any more today, it is what that the purchasers manage less and less to know the origin of the products which they consume, even some- times the salesmen themselves, which judicious to sell them, are unaware of their origin.

\subsection{Ethnicity and the Prism of Identity: Case of Hybrid Products}

The multiplication of origin product signals led to complex the evaluations of the consumers and the treatment of the effect "country of origin" by the researchers. Moreover, although the bonds between the product and nationality are often studied on the basis of influence of the "made in", such a label remains an element among so many others which ensure the consumer's perception of the products nationality. Indeed, Usunier and Lee [11] show that the attribution of the product origin must take into account several components with knowing the national image of the generic product, the national image of the manufacturer, the image diffused by brand and the image of "made in" label [12] mentioned on the product.

For all these reasons, it would be definitely difficult for the consumer to evaluate a product whose indicator of origin is missing or when several countries are implied in the process of its manufacture. It is for example the case of Honda cars which are manufactured in the United States and which could not be perceived as not being American but rather like Japanese cars [13]. Still, the example of Pontiac Mans car which is conceived in Germany and assembled in South Korea with components coming from seven other countries like France, United States, Canada, Japan, Australia, South Korea and Singapore [14]. In addition, the proliferation of hybrid pro- 
ducts, explained by the multiplication of delocalization and universalization of the production, which creates a favourable ground with the development of counterfeits, which complexes even more the things for the consumers who do not seem not formed enough to be able to distinguish an imitated product (counterfeits) from a licensed product [15].

Also it is necessary, as of now, to expect that the proliferation of hybrid products has negative effects on the product ethnicity. Of course, and as we already saw previously, product ethnicity represents the whole of bonds stereotypic established by the consumer between countries and products, thus it wouldn't be difficult for this consumer who represents to establish such associations when they are hybrid products coming from various countries? Admittedly, the relocalization of the production generates some uncertainty in the consumer what results in reducing its waiting as for the product quality. Consequently, of harmful effects can affect the sales unless the manufacturers provide more efforts to convince the consumer of unchanged product quality [16]. Thus let's think that the development growing of the multinational production seems to deteriorate the product ethnicity to some extent, owing to the fact that indicators of origin will be scrambled and not easily exploited by the consumers. Indeed, the diversification of the countries implied in the manufacturing process of a product is likely to make compromise the recognition of its origin near the consumers. In other words, the hybrid production can create a distance between the geographical products and their origins so much that the identification of products considered "typical of the country" can be dissimulated.

However, some experts in marketing confirm that it is possible for the companies to succeed as long as the product's brand enjoys a strong image independently of the original site of its production since are the strongest brand which narrowly connect the consumers to their origin countries [16]. In accordance with this, Samiee (1994) [17] showed that a brand with strong reputation can be adopted by the consumer like an attribute more important than the country of origin.

In this context, a correlative question is tempting: wouldn't it be judicious for the companies to revise their strategies of transfer images of their products abroad?

\section{Conclusions}

To study the phenomenon of product ethnicity within the framework of a multinational production returns to the stakes revealed by the world economical situation at the present time. Indeed, the increased proliferation of hybrid products of various origins accentuated by the strategies of origin jamming is likely to dissolve the identity of the products to see even companies, which could deteriorate the bonds stereotypic "product-country" establish by the consumer during the product evaluation.

That resulted in thinking of the need for the revision of origin marking strategies in order to protect the identity from the products and to facilitate their evaluation by consumers. In this respect, it is to be stressed that former work which clarified the importance to study the bonds stereotypic "product-country" [1] or information "product ethnicity" [3] already showed that this variable forms a kind of guarantee for particular countries because it seems able to improve some origins of products, as it makes it possible to the managers to defend the position of their companies and to face competition on the international market, by associating important dimensions of product category with those of country image.

However, with the globalization of market and the internationalization of trade, "the representations of local consumers remain partly local” [3]. In other words, it could exist important shifts a priori enters, on the one hand, the product ethnicity as the company conceives it, and on the other hand the representation available to the local consumers as for this product.

Also, wouldn't it be judicious to think of reconciliation between the globalization and product ethnicity to the direction only the ethnicity, which usually perceived in a logic of localization, from now on, is registered in a transnational space without to dissolve the product identity?

\section{REFERENCES}

[1] M. Roth and J. B. Rome, "Matching Product Category and Country Image Perceptions: A Framework for Managing Country-of-Origin Effects,” Journal of International Business Studies, Vol. 23, No. 3, 1992, pp. 477-497.

[2] Kühn and Weiss, "The Brand Image of Switzerland, a Chance for the Companies," Economic Life: Review of Economic Policy, Vol. 6, 2003, p. 56.

[3] J.-C. Usunier, "Product Ethnicity: An Exploratory Approach,” Decision Marketing, No. 27, 2002, pp. 35-49.

[4] J. R. Rossiter and A. M. Chan, "Ethnicity in Business and Consumer Behavior,” Journal of Business Research, Vol. 42, No. 2, 1998, pp. 127-134. doi:10.1016/S0148-2963(97)00113-6

[5] P. Wade, "Race and Ethnicity in Latin America,” Pluto Press, London, Sterling, 1997.

[6] E. Cunin, "Ethnicity Revisited by the Globalization,” $\mathrm{Au}$ trepart, Vol. 38, 2006, pp. 3-13.

[7] C. Reierson, "Attitude Changes toward Foreign Products," Journal of Marketing Research, Vol. 4, No. 4, 1967, pp. 385-387. doi: $10.2307 / 3149879$

[8] J.-C. Usunier and G. Cestre, "Product Ethnicity: Revisit- 
ing the Match between Products and Countries,” Journal of International Marketing, Vol. 15, No. 3, 2007, pp. 3272. doi:10.1509/jimk.15.3.32

[9] M. Koromyslov, "Impact of Luxury Delocalization on the Consumer's Attitudes: The Case of the French Luxury Houses," Thesis of Doctorate in Sciences of Management, Administration Institute of the Companies, University Nancy II, Nancy, 2009.

[10] P. Gabriel and B. Urien, "Values of Consumption and Territorial Origin of the Products," Decisions Marketing, Vol. 43, No. 44, 2006, pp. 41-54.

[11] J.-C. Usunier and J. A. Lee, "Marketing across Cultures," 4th Edition, Prentice Hall, Upper Saddle River, 2005.

[12] A. Nagashima, “A Comparative ‘Made-In’ Product Image Survey among Japanese Businessmen,” Journal of Marketing, Vol. 41, No. 3, 1977, pp. 95-100. doi: $10.2307 / 1250943$

[13] F. Smaoui, "Perceived Origin Effect of the Brand Name on Consumer's Perceptions: Case of Emerging Countries Consumer," 8th International Congress Marketing Trends, Paris, 16-17 January 2009, pp. 32-72.

[14] R. Ettenson and G. Gaeth, "Commentary: Consumer Perceptions of Hybrid (Bi-National) Products," Journal of Consumer Marketing, Vol. 8, No. 4, 1991, pp. 13-18. doi:10.1108/07363769110035117

[15] I. Phau and G. P. Prendergast, "Tracing the Evolution of Country of Origin Research: In Search of New Frontiers,” Journal of International Marketing and Exporting, Vol. 4, No. 2, 1999, pp. 71-83.

[16] G. Schweiger, T. Otter and A. Strebinger, "The Influence of Country of Origin and Brand on Product Evaluation and the Implications Thereof for Location Decisions," CEMS Business Review, Vol. 2, 1997, pp. 5-26.

[17] S. Samiee, "Customer Evaluation of Products in a Global Market,” Journal of International Business, Vol. 25, No. 3, 1994, pp. 579-604. 